\title{
A CONSTRUÇÃO DA CADEIA REFERENCIAL EM TEXTOS DE ESTUDANTES UNIVERSITÁRIOS
}

\author{
Janice Helena Chaves MARINHO* \\ Gustavo Ximenes CUNHA **
}

- RESUMO: Neste artigo, focalizando a construção da cadeia referencial em fragmentos de textos acadêmicos, mostramos que a análise da forma de organização tópica dos textos possibilita a percepção de dificuldades que estudantes universitários manifestam nessa construção. Por meio das análises, identificamos e explicamos fragilidades na construção da cadeia referencial, tais como ambiguidades no reconhecimento dos tópicos, bem como dificuldades na introdução de novas informações e na manutenção de um tópico discursivo. Ainda, com as análises, verificamos que os textos acadêmicos constituem índices essenciais para a avaliação das capacidades de uso da linguagem de seus produtores. Por isso mesmo, essas análises podem funcionar como um ponto de partida precioso para o planejamento de atividades que auxiliem o estudante no desenvolvimento das habilidades necessárias para a construção da cadeia referencial de novos textos. Assim, evidenciamos que o Modelo de Análise Modular do Discurso constitui uma abordagem bastante relevante para o estudo de textos produzidos por estudantes universitários.

- PALAVRAS-CHAVE: Textos acadêmicos. Cadeia referencial. Abordagem modular.

Em consonância com diretrizes governamentais para o ensino de língua(gem), como os Parâmetros Curriculares Nacionais (PCN), um número crescente de publicações tem procurado apresentar ao leitor modelos teóricos úteis ao estudo do discurso em sala de aula, nos diferentes níveis de ensino. Deixando de lado a perspectiva gramatical tradicional, o surgimento desses trabalhos de natureza teórica e aplicada mostrou ser possível fazer do discurso um objeto sistemático de ensino e aprendizagem, e deu ao professor mais condições de auxiliar o aluno do ensino fundamental, médio ou superior a ter domínio da linguagem que emprega nas diferentes situações do cotidiano.

Nessa mesma perspectiva, este artigo considera a linguagem um fenômeno de grande complexidade, uma vez que tanto na produção quanto na interpretação do discurso os interlocutores realizam um número bastante elevado de

\footnotetext{
* UFMG - Universidade Federal de Minas Gerais. Faculdade de Letras. Belo Horizonte - MG - Brasil. 31270-010 jhcmar@uol.com.br

** UNIFAL - Universidade Federal de Alfenas. Instituto de Ciências Sociais Aplicadas. Varginha - MG - Brasil. 37048-395 - ximenescunha@yahoo.com.br
} 
operações linguístico-discursivas e sócio-cognitivas. Dessas operações, fazem parte a seleção do gênero de discurso em função do contexto em que se dá a interação, a escolha do léxico e das estruturas sintáticas, a decisão sobre os tipos de sequências (narração, descrição, argumentação), a construção da cadeia referencial, etc. Como essas habilidades de uso da linguagem são muitas e complexas, neste trabalho optamos por centrar a atenção em um fenômeno discursivo, que é a construção da cadeia referencial em textos produzidos por estudantes universitários.

Nossa discussão se baseia na análise desses textos, porque consideramos, em conformidade com Machado (2003), que eles carregam índices essenciais para a avaliação das capacidades de uso da linguagem dos estudantes e para o planejamento de atividades que possam levar a seu desenvolvimento. E, ao tratar apenas do fenômeno da construção da cadeia referencial, acreditamos ser possível abordá-lo de maneira mais aprofundada, mostrando que o estudo desse plano de estruturação dos textos, com base nos postulados de um modelo de análise do discurso, é fundamental para que o professor possa auxiliar o estudante a compreender o processo de construção textual.

Para alcançar o objetivo deste trabalho, expomos inicialmente o modelo teórico que orienta nossas análises, o Modelo de Análise Modular do Discurso. Em seguida, apresentamos o estudo da construção da cadeia referencial. Nesse estudo, mostramos, por meio da análise de fragmentos dos textos produzidos por estudantes universitários, que o modelo por nós adotado possui um conjunto de ferramentas eficazes para descrever e explicar inadequações que muitas vezes se manifestam na construção da cadeia referencial em textos.

\section{Modelo de Análise Modular do Discurso}

Para a descrição e exploração de todos os tipos de discurso, de quaisquer documentos autênticos, faz-se necessária a utilização de um instrumento geral de análise que seja capaz de dar conta da complexa organização de discursos. Para atender a essa demanda, Roulet e equipe (ROULET; FILLIETTAZ; GROBET, 2001) propõem um modelo de organização do discurso o qual permite que se estudem todos os aspectos ligados à interação verbal. Nessa perspectiva, o Modelo de Análise Modular do Discurso constitui um instrumento que procura integrar, num quadro unificado, os componentes linguístico, textual e situacional (ROULET; FILLIETTAZ; GROBET, 2001; MARINHO; PIRES; VILELA, 2007). Como assinala Pires (1997, p.27), o modelo de análise modular possibilita distinguir, e não dissociar, o que é distinto, sendo um modelo "[...] capaz de conciliar as dimensões lingüística, discursiva e situacional de uma forma dinâmica, sem, entretanto, modificar a lógica da organização de cada uma delas." 
Segundo Roulet (1999b, p.145), esse modelo:

[...] pressupõe uma dupla exigência: a) decompor a organização complexa do discurso em um número limitado de sub-sistemas (ou módulos), reduzidos a informações as mais elementares; b) descrever, de maneira bastante precisa, a forma através da qual essas informações podem ser combinadas para dar conta das diferentes alternativas de organização dos discursos analisados.

Dessa forma, cada módulo é descrito de forma independente e reduzido a seus elementos mais simples, numa primeira fase da análise, chamada de découplage ${ }^{1}$. Em seguida, essa fase é completada por uma segunda fase, a de couplage das informações obtidas com a descrição dos módulos, permitindo o tratamento da complexidade dos discursos em diferentes formas de organização².

No modelo modular, o estudo da construção da cadeia referencial diz respeito à maneira como os interlocutores fazem a gestão e o encadeamento dos objetos de discurso no desenvolvimento da interação, ativando, desativando e reativando referentes, e ocorre no interior da forma de organização tópica. O estudo dessa forma de organização se faz em três etapas. Inicialmente, estuda-se a forma de organização informacional, que trata da continuidade tópica (ou temática) bem como da progressão das informações que são ativadas nos textos. Em seguida, na segunda etapa, os resultados da primeira são combinados com a análise do módulo hierárquico, que define os constituintes de base da estrutura dos textos e descreve as relações existentes entre esses constituintes. Por fim, a terceira etapa combina a análise informacional com a análise do módulo referencial, que trata das ações linguageiras e não linguageiras realizadas ou designadas pelos locutores, bem como dos conceitos implicados em tais ações.

A sequência deste artigo apresenta o estudo de cada uma dessas etapas, focalizando fragmentos extraídos de textos produzidos por estudantes universitários. Nesse estudo, mostraremos em que medida os instrumentos de análise propostos pelo modelo possibilitam ultrapassar uma análise intuitiva das produções discursivas e, consequentemente, planejar de forma mais segura estratégias adequadas ao desenvolvimento das habilidades do estudante em construir a cadeia referencial dos textos que produz.

\footnotetext{
1 O modelo propõe os módulos sintático e lexical (dimensão linguística); hierárquico (dimensão textual); referencial e interacional (dimensão situacional).

2 As formas de organização consideradas pelo modelo são fono-prosódica, semântica, relacional, informacional, enunciativa, sequencial, operacional, tópica, polifônica, composicional, periódica e estratégica.
} 


\section{A forma de organização informacional}

No modelo modular, o estudo dessa forma de organização resulta da combinação de informações hierárquicas, sintáticas, lexicais e referenciais. Seu objetivo é analisar a estrutura informacional de cada ato - considerado a menor unidade de análise - e descrever a sua inserção na estrutura do texto, por meio das formas de progressão informacional que se observam na sucessão dos atos. Com esse estudo, procura-se dar conta da continuidade dos encadeamentos entre as informações que são ativadas, a todo momento, no processamento do texto.

Conforme Grobet (2000), um ato pode ter diversos pontos de ancoragem, situados em diferentes níveis da memória discursiva ${ }^{3}$. Desses pontos de ancoragem, há os que se situam num nível imediato, enquanto outros se situam num nível mais profundo, chamado d'arrière-fond. Essa distinção é importante, porque permite tratar a multiplicidade de elementos temáticos que um mesmo segmento linguístico pode apresentar (GROBET, 2000).

O ponto de ancoragem imediato é constituído pela informação mais diretamente acessível da memória discursiva na qual o ato se encadeia. Esse ponto de ancoragem é igualmente chamado de "tópico", o qual é definido por Grobet como "[...] uma informação identificável e presente na consciência dos interlocutores, que constitui, para cada ato, o ponto de ancoragem mais imediatamente pertinente, mantendo uma relação de 'a propósito' (aboutness) com a informação ativada por esse ato." (ROULET; FILLIETTAZ; GROBET, 2001, p.255). Já o ponto de ancoragem d'arrière-fond, ou ponto de ancoragem de segundo plano, é constituído por informações que, como dito, se situam em níveis mais profundos da memória discursiva.

Os pontos de ancoragem imediatos, ou tópicos, podem ser verbalizados no discurso por traços anafóricos, como pronomes ou expressões definidas. Esses traços são chamados de traços tópicos. Entretanto, em discursos monologais complexos e, principalmente, em diálogos, os tópicos podem ficar implícitos, isto é, podem não ser verbalizados por traço tópico. Quando isso ocorre, para encontrar o tópico, é preciso buscar a informação mais diretamente acessível ou mais imediatamente pertinente no cotexto ou na situação de comunicação em que o propósito se ancora (MARINHO, 2005; CUNHA, 2008).

O estudo da forma de organização informacional se completa com a análise dos tipos de progressões informacionais ou modos de encadeamento que se observam na sucessão dos atos. Os modos de encadeamento considerados pelo modelo modular são:

3 A memória discursiva compreende "[...] os diversos pré-requisitos culturais (normas comunicativas, lugares argumentativos, saberes enciclopédicos comuns, etc) que servem de axiomas aos interlocutores para conduzir uma atividade dedutiva." (BERRENDONER, 1983, p.230-231). 
- Encadeamento ou progressão linear: ocorre quando o tópico de um ato tem origem no propósito precedente, ou seja, quando ele tem origem na informação que acaba de ser ativada.

- Encadeamento ou progressão com tópico constante: ocorre quando uma sucessão de atos se ancora num mesmo tópico.

- Encadeamento à distância: ocorre quando o tópico de um ato tem origem não no propósito que acaba de ser ativado, mas em um propósito mais distante.

Feita a apresentação sucinta da forma de organização informacional, mostraremos de que maneira o seu estudo pode ser aplicado na compreensão das estratégias de formulação textual utilizadas por estudantes universitários. ${ }^{4}$

Na produção de textos acadêmicos escritos, os autores realizam diferentes operações, como, por exemplo, as de estruturação tópica, de condensação de ideias, de supressão de redundâncias e ambiguidades, de explicitação dos tipos de relações estabelecidas entre os elementos linguísticos, de reformulação ou reorganização das sequências discursivas, etc. Os autores realizam essas operações, em função da situação de produção do texto, situação que se caracteriza por um grau relativamente alto de formalidade, já que o texto será lido e avaliado por um professor, no caso dos textos em que vamos basear nossa discussão; por uma banca, no caso de monografias, dissertações e teses, ou por pareceristas, no caso de artigos científicos (MARINHO, 2002; MOTTA-ROTH; HENDGES, 2010).

Tendo em vista essas condições de produção do texto acadêmico, espera-se que, no nível informacional, o autor construa um texto em que o reconhecimento dos tópicos dos atos não seja ambíguo, não exigindo grandes esforços de processamento por parte do leitor. Da mesma forma, espera-se que o autor, a partir das leituras e discussões desenvolvidas dentro e fora da sala de aula, demonstre um domínio satisfatório do assunto abordado, construindo um texto em que haja a introdução sucessiva de informações de acordo com a orientação argumentativa delineada e em que essas informações sejam relativas e pertinentes ao universo textual em construção. Em suma, espera-se que, na produção de textos acadêmicos escritos, sejam evitadas ambiguidades prejudiciais à construção da coerência por parte do leitor e haja movimentos constantes de projeção (progressão) e de retroação (continuidade) na construção da cadeia referencial (MACHADO, 2003; KOCH, 2006; RONCARATI, 2010).

\footnotetext{
A título de esclarecimento, os fragmentos de textos utilizados para ilustrar nossas discussões fazem parte do corpus da pesquisa desenvolvida em Marinho (2002) e foram produzidos por estudantes universitários do primeiro período do curso de Letras. Esses alunos produziram os textos atendendo à solicitação da professora, após a leitura de dois livros (Língua e Liberdade, de Celso Pedro Luft, e Por que (não) ensinar gramática na escola?, de Sírio Possenti) e a discussão do tema em sala de aula. Vale esclarecer que todos os fragmentos analisados serão aqui reproduzidos tal como foram produzidos por seus autores.
} 
Mas não raro os textos produzidos em ambiente universitário apresentam inadequações no nível informacional, as quais decorrem muitas vezes da dificuldade do estudante em apreender as condições de produção de seu texto, das quais fazem parte a finalidade da interação e a identidade do outro com quem dialoga.

Assim, os textos podem se caracterizar pela imprecisão na ancoragem dos atos em uma informação da memória discursiva. Nesse caso, um mesmo ato apresenta uma multiplicidade não intencional de pontos de ancoragem, não sendo possível decidir de maneira segura qual desses pontos constitui o tópico e quais constituem pontos de ancoragem de segundo plano. A ambiguidade na identificação do tópico de um ato pode comprometer a legibilidade de um texto, já que o leitor precisará dispensar maiores esforços de interpretação, valendo-se de outros planos de estruturação do texto para decidir pelo tópico que considera o mais pertinente. Um exemplo desse caso pode ser verificado na estrutura informacional deste fragmento: ${ }^{5}$

\section{Quadro 1 - Estrutura informacional do fragmento 1}

\begin{tabular}{|l|l|}
\hline (14) (a propósito do ensino da gramática) A radicalização & \\
do ensino na sua forma tradicional, & \\
(15) onde [no ensino] a gramática está em posição de & Progressão linear \\
destaque, & Encadeamento à distância \\
(16) (a radicalização do ensino) deve ser revista, \\
(17) (a radicalização do ensino deve ser revista) de forma & Tópico constante \\
a dedicar maior parte do tempo para trabalhos com & \\
obras e textos de todos os níveis & \\
(18) os quais [os trabalhos] a gramática encontra-se & Progressão linear \\
implícita & \\
(19) (nos trabalhos) e o aluno possa desenvolver seu & Tópico constante \\
raciocínio, sem censuras, & \\
(19) e o aluno possa desenvolver seu raciocínio, sem & Encadeamento à distância \\
censuras, & \\
(20) (o aluno) tornando-se um brilhante escritor, & Progressão linear \\
(21) os [os alunos] que possuem talento, & Tópico constante \\
(22) e (os alunos tornando-se) verdadeiros conhecedores & Tópico constante \\
da língua materna. & \\
\hline
\end{tabular}

Fonte: Elaboração própria.

\footnotetext{
Na estrutura informacional, os atos ocupam a coluna esquerda do quadro e são numerados. Os traços que verbalizam o tópico são apresentados em negrito; o tópico assim verbalizado aparece entre colchetes, depois do traço. Quando o tópico é implícito, ou seja, não verbalizado por traço tópico, ele aparece entre parênteses, no início do ato. Os termos em itálico são os traços de ponto de ancoragem de segundo plano. Na coluna direita, apresentam-se os tipos de progressão informacional.
} 
No ato (19), o tópico tanto pode ser interpretado como "nos trabalhos" quanto "o aluno". Se ele for a informação "nos trabalhos", o tópico de (19) é o mesmo de (18), e ocorre uma progressão por tópico constante, ou seja, os objetos de discurso ou propósitos ativados por esses atos sucessivos se encadeiam num mesmo tópico. Mas, se ele for a informação "o aluno" há a reativação de uma informação da memória discursiva com origem em atos precedentes: "(09) $\mathbf{O}$ aluno (10) quando se vê diante de um texto para ser analisado (11) ou até mesmo criar um, (12) ele se mostra incapaz". Caso "o aluno" seja o tópico de (19), ocorre um encadeamento à distância.

De maneira preliminar, é possível dizer que, das duas informações candidatas ao tópico de (19), "nos trabalhos" é a que apresenta maior grau de saliência na memória discursiva, porque é o tópico do ato anterior. Entretanto, a possibilidade de a informação "o aluno" ser tópico precisa ser levada em conta.

Em (19), a expressão "o aluno" é introduzida por um artigo definido, o qual tem como função indicar que a expressão de que participa categoriza referente dado ou já introduzido na memória discursiva (GROBET, 1999, 2000; KOCH, 2006; NEVES, 2006). Além disso, essa expressão exerce o papel sintático de sujeito. Nos trabalhos que estudam o tópico em uma perspectiva frasal, o sujeito costuma ser visto como um candidato forte ao papel de tópico, já que é desse termo que o restante da oração costuma tratar (PERINI, 2008). Como a forma de organização informacional resulta da combinação de informações referenciais, hierárquicas, lexicais e sintáticas, o modelo modular nos permite considerar o papel do artigo definido e rever a perspectiva frasal do tópico, entendendo que a expressão que funciona como sujeito, se um artigo definido a integra, apresenta a possibilidade de funcionar como o traço tópico, ou seja, como a marca sintática que sinaliza a ancoragem do ato no tópico (GROBET, 1999, 2001).

Nesse sentido, a ambiguidade na atribuição do tópico de (19) se deve ao que podemos chamar de um conflito de níveis de análise. No nível referencial, o grau maior de acessibilidade de "nos trabalhos" faz com que essa informação pareça ser o tópico de (19). Mas, no nível sintático, a expressão "o aluno", exercendo a função de sujeito, remete a uma informação ativada em atos precedentes que também é candidata ao papel de tópico de (19).

Embora a análise informacional, tal como desenvolvida no Quadro 1, permita a identificação da multiplicidade de pontos de ancoragem para um mesmo ato, essa análise se faz de maneira pouco precisa, porque não explica o que motiva essa multiplicidade e não permite decidir por uma ou outra interpretação. Como veremos adiante, no caso do ato (19) do fragmento do Quadro 1, o recurso à estrutura hierárquica é que vai permitir uma análise mais técnica, que ultrapasse a linearidade da estrutura informacional, por levar em conta a hierarquia das informações mobilizadas ao longo do texto. 
Além dessa imprecisão na ancoragem dos atos em seus tópicos, os textos produzidos por estudantes universitários podem revelar fragilidades na realização da progressão textual. Nesse caso, o texto não introduz informações pertinentes em relação ao universo textual em construção e/ou não desenvolve de maneira satisfatória as informações previamente introduzidas. Além disso, os textos que podem ser assim caracterizados apresentam uma grande quantidade de atos ligados a informações da memória discursiva por tópico constante. Nesse tipo de encadeamento, todos os atos acrescentam informações sobre um mesmo tópico. É o que se verifica na estrutura informacional deste trecho:

\section{Quadro 2 - Estrutura informacional do fragmento 2}

(21) (o ensino tradicional) O aluno não faz redação para aplicar a língua,

(22) (o aluno) faz para o professor corrigir,

(23) e (a redação) dependendo da nota adquirida,

(24) (o aluno) desenvolvem uma relação negativa com a língua materna,

(25) (o aluno) torna-se inseguros

(26) (o aluno) e bloqueiam sua criatividade,

(27) (o aluno) sufocam a expressão pessoal.

(28) O estudante [o aluno] fica sobrecarregado de inutilidades,

(29) (o estudante/o aluno fica sobrecarregado de inutilidades) faltando tempo para exercitar sua capacidade comunicativa,

(30) (o aluno) crescer em linguagem,

(31) (o aluno) melhorar seu nível,

(32) (o aluno) aumentar seu vocabulário,

(33) (o aluno) estudar semântica, sintaxe mais elaborada, recursos e técnicas de expressão, interpretação e redação de textos,

(34) (o aluno) tomar consciência das potencialidades de sua língua

(35) e (o aluno) dominar a escrita,

(36) (o aluno) só aprendem nas aulas o que dificilmente vão usar.
Progressão linear

Encadeamento à distância

Encadeamento à distância

Tópico constante

Tópico constante

Tópico constante

Tópico constante

Tópico constante

Tópico constante

Tópico constante

Tópico constante

Tópico constante

Tópico constante

Tópico constante

Tópico constante

Tópico constante

Fonte: Elaboração própria.

Nesse trecho, a maior parte dos atos traz informações sobre o tópico "o aluno". Do ato (21) ao (27), o autor aponta os malefícios do ensino tradicional da língua para o desenvolvimento do aluno. No restante do fragmento, o autor informa que 
a redação - vista "como aplicação de regras gramaticais, onde [os professores] assinalam todos os erros de grafia, pontuação, sintaxe" - sobrecarrega o aluno de inutilidades, não permitindo o desenvolvimento de habilidades que o autor considera importantes. Assim, o texto é elaborado como uma espécie de lista. Após a ativação da informação "o aluno", no ato (21), o autor se ocupa de informar, de um lado, malefícios que a redação traz para o aluno e, de outro, habilidades que esse ensino não permite ao aluno desenvolver.

Nesse fragmento, que se vale do recurso da sobreposição de informações em um mesmo tópico, demonstra-se uma dificuldade no estabelecimento da progressão textual. Isso porque, em primeiro lugar, como ressaltamos, a maior parte das informações se ancora em um tópico, não ocorrendo uma derivação de novos tópicos a partir de "o aluno". Em segundo lugar, muitas das informações ativadas pelos atos são pouco relevantes do ponto de vista semântico, porque são genéricas e não apresentam diferenças significativas em relação ao que já havia sido informado em atos precedentes. Por exemplo, bloquear a criatividade (26) e sufocar a expressão pessoal (27) são informações muito semelhantes. Da mesma forma, crescer em linguagem (30), melhorar o nível (31) e aumentar o vocabulário (32), além de serem informações muito vagas, parecem ter um conteúdo semântico muito parecido.

O recurso de construção textual, ilustrado no trecho acima, de encadear várias informações pouco significativas em um mesmo tópico revela a dificuldade do autor de proceder a uma discussão significativa do tópico de que trata. Assim, o texto parece resultar da articulação pouco consistente de informações do senso comum com informações recentemente aprendidas no meio universitário.

Como se percebe, a análise da estrutura informacional é um instrumento importante para se detectarem falhas na progressão textual de uma produção discursiva, porque é por meio dela que se verificam a ancoragem de vários atos em um mesmo tópico, bem como a natureza das informações ativadas sobre esse tópico. Entretanto, a construção de um texto por meio da sobreposição de informações num tópico só pode ser compreendida em profundidade com o auxílio da estrutura conceitual. Como veremos adiante, essa estrutura permite verificar o processo de derivação entre conceitos que subjaz à estrutura informacional, mostrando que, nos textos em que a progressão textual é incipiente, há uma dificuldade em transformar um conceito derivado em um novo conceito primitivo, recurso com o qual o texto poderia progredir, sem perder a continuidade.

Diferentemente do fenômeno abordado anteriormente, há textos que se caracterizam pela dificuldade no estabelecimento da continuidade textual, na medida em que o autor sempre encadeia os atos nas informações ativadas nos atos imediatamente precedentes, dificultando a percepção do tópico discursivo 
e, consequentemente, a construção de um universo textual coerente. Vejamos a estrutura informacional deste fragmento:

\section{Quadro 3 - Estrutura informacional do fragmento 3}

(12) (aprendizado de uma língua) Se o precoce domínio da linguagem falada acontece

(13) (o precoce domínio da linguagem falada acontece) Progressão linear justamente porque somos expostos, desde a infância, à prática auditiva e de conversação,

(14) onde [na prática auditiva e de conversação] a repetibilidade e a correção dos erros representam fatores determinantes ao completo domínio da oratória,

(15) é de se esperar que o mesmo sucesso [o domínio da oratória/da linguagem] seja alcançado no ensino da linguagem escrita,

(16) (no ensino) bastando a intensiva exposição do aluno à leitura e confecção de textos,

(17) (no ensino) aplicando-se a correção quando necessário.

(18) (aprendizado de uma língua) Neste processo de aprendizagem,

(19) (aprendizado de uma língua) a gramática estaria inserida como um elemento secundário,

(20) (elemento secundário) a ser consultado (assim como os dicionários) sempre que necessário,

(21) (elemento a ser consultado sempre que necessário) ou seja, quando surgirem dúvidas relacionadas à correção gramatical durante a produção literária.

Fonte: Elaboração própria.

Nesse fragmento, a maior parte dos atos se ancora em informação ativada no ato imediatamente anterior. Por meio desse recurso de construção textual, uma informação recentemente ativada torna-se de imediato o tópico do ato subsequente. O texto se constrói assim com um excesso de informações novas, o que pode levar o leitor a experimentar dificuldade em compreender qual é o "fio condutor" do texto. Se no fragmento anterior o fio condutor "o aluno" estava excessivamente definido, dele não se derivando outras informações relevantes, aqui novas informações são constantemente ativadas e introduzidas na memória discursiva, dificultando o reconhecimento de um fio condutor. Esse tipo de formulação textual pode levar um leitor a se perguntar: "Mas do que trata o texto? Do aprendizado espontâneo de uma língua, do 
domínio da oratória, do ensino regular de língua, da gramática como elemento secundário no ensino?".

Ainda que essa análise informacional seja pertinente, pois revela a predominância de atos ancorados na informação ativada no ato imediatamente anterior, o recurso à estrutura conceitual, como veremos adiante, constitui um instrumento bastante pertinente para entender o que ocorre em textos que apresentam esse tipo de inadequação no estabelecimento da continuidade. Com a acoplagem das estruturas informacional e conceitual do fragmento do Quadro 3, será possível entender que essa inadequação se deve a uma proliferação incessante de conceitos derivados e à dificuldade na percepção de uma entidade tópica, isto é, do conceito primitivo de que se originam os demais.

A análise da forma de organização informacional, tal como desenvolvida neste item, se mostra interessante, na medida em que evidencia os diferentes modos de encadeamento dos atos em pontos de ancoragem e permite revelar fragilidades na construção da cadeia referencial dos textos. Mais especificamente, a análise dessa forma de organização possibilita apreender as manobras que o autor realiza para construir a cadeia referencial do texto, manobras que, quando identificadas na produção textual de um estudante, podem funcionar como um ponto de partida para a elaboração das estratégias de ensino adequadas ao desenvolvimento da capacidade de construção do texto. Nesse sentido, a análise permite uma espécie de "diagnóstico" quanto às habilidades do estudante no que se refere às estratégias de construção da cadeia referencial.

Entretanto, como vimos, a análise realizada nessa forma de organização, ainda que ultrapasse uma abordagem meramente intuitiva, não permite uma explicação satisfatória dos fenômenos observados anteriormente. Isso porque uma compreensão mais precisa das estratégias de construção da cadeia referencial implica a consideração de outros planos do discurso. Assim, para poder explicar as escolhas dos autores quanto às formas de encadeamento, deve-se proceder à couplage (combinação) das informações extraídas da análise informacional com as obtidas por meio da análise dos módulos referencial e hierárquico.

Dessa forma, as etapas seguintes deste trabalho buscam descrever a análise da forma de organização tópica em toda a sua complexidade, mostrando como as estruturas hierárquica e conceitual podem ser úteis numa compreensão mais segura das fragilidades detectadas na construção da cadeia referencial de textos produzidos por estudantes universitários. 


\section{Forma de organização tópica}

No Modelo de Análise Modular, considera-se que o estudo do tópico não constitui um processo elementar, uma vez que envolve mais do que apenas a descrição da estrutura informacional do discurso. Como vimos, essa estrutura fornece uma análise linear do modo como cada ato se liga a pontos de ancoragem previamente estocados na memória discursiva.

Por essa razão, uma série de questões ligadas à gestão dos referentes no discurso não recebe um tratamento específico, e o analista não pode assim explicar, por exemplo, por que algumas informações parecem ter uma importância maior no texto, enquanto outras parecem ter uma importância secundária, ou decidir de maneira mais segura qual ponto de ancoragem funciona como o tópico de um ato. A estrutura informacional também não possibilita compreender o processo de derivação entre as informações, o qual subjaz aos movimentos de progressão e de continuidade de um texto. Dessa forma, para a compreensão dos fenômenos observados anteriormente em textos produzidos por estudantes, não é suficiente a análise da estrutura informacional. Essa compreensão implica mobilizar estruturas resultantes do estudo de outros módulos do discurso (GROBET, 2000; MARINHO, 2002; CUNHA, 2009).

Assim, o modelo propõe completar a forma de organização informacional, dinamizando a estrutura resultante de seu estudo, por meio da combinação progressiva dessa estrutura com informações resultantes do estudo de módulos no interior da forma de organização tópica do discurso. Inicialmente, combinamse os resultados obtidos na primeira etapa de análise com o estudo do módulo hierárquico sobre as relações entre os constituintes do texto. Em seguida, os resultados obtidos na primeira etapa são combinados com o estudo do módulo referencial sobre os conceitos mobilizados na interação.

\section{Módulo hierárquico}

Antes de proceder à combinação das estruturas informacional e hierárquica, é importante apresentar, ainda que sucintamente, o módulo hierárquico.

Conforme Roulet (1999a), todo discurso deve ser concebido como um processo de negociação entre interlocutores, por meio do qual estes apresentam uma informação, formulam uma pergunta ou uma resposta, desenvolvem uma discussão, etc. Deve-se partir da hipótese de que toda atividade linguageira apresenta o seguinte esquema de negociação: 
Figura 1 - Esquema de negociação geral

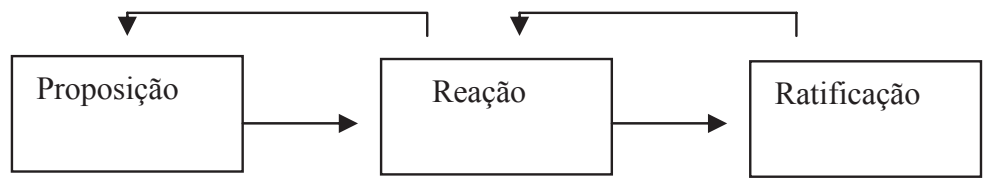

Fonte: Elaboração própria.

A negociação pode-se desenvolver de maneira linear, num só nível, como está mostrado na Figura 1, sendo hierarquicamente representada por uma troca formada de três intervenções, ou pode apresentar ainda níveis secundários, diferenciados, conforme a necessidade ou não de obtenção de mais informações, fazendo-se necessária a abertura de troca(s) secundária(s) (ROULET, 1999a).

Gerada nesse módulo, a estrutura hierárquica possibilita representar esse processo de negociação, permitindo visualizar as hierarquias e as relações existentes entre os constituintes do texto, a saber: de dependência, independência e interdependência (ROULET, 1996, 1999a, 2003). Os constituintes dependentes são os que têm sua presença ligada à presença de outro. O constituinte dependente, que tanto pode ser uma troca, quanto uma intervenção ou um ato, é chamado de subordinado e pode ser suprimido do texto sem comprometer sua estrutura global. A ele se relaciona o constituinte, que pode ser uma intervenção ou um ato, chamado de principal, por ser o responsável pelo sentido e pela força ilocucionária da intervenção. A relação de independência se dá quando a presença de um constituinte independe da de outro, como é o caso das intervenções ou atos coordenados. A relação de interdependência ocorre quando um constituinte da estrutura hierárquica não pode existir sem o outro; por exemplo, uma intervenção de resposta tem sua existência dependente da de uma intervenção de pergunta e vice-versa.

No caso dos textos produzidos por estudantes universitários, partimos da hipótese de que há uma negociação que pode ser assim esquematizada:

Figura 2 - Esquema de negociação do texto universitário

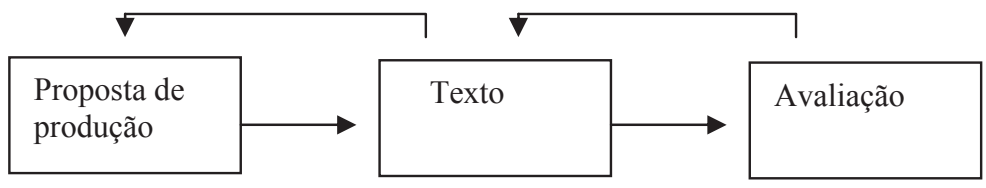

Fonte: Elaboração própria. 
Como resposta à proposta de produção do texto pelo professor, abordando o problema do ensino da gramática na escola e reagindo às discussões feitas em sala de aula, o estudante constrói seu texto, que será posteriormente avaliado pelo mesmo professor.

Dessa forma, os textos produzidos por estudantes universitários apresentam uma estrutura de intervenção. Conforme a forma de negociação presente no texto, essa intervenção pode ser complexa e, portanto, composta por outras intervenções, que, por sua vez, se compõem por atos seguidos de uma nova intervenção ou por outras intervenções, etc., cumprindo-se a exigência de se chegar à completude dialogal, ou seja, ao fechamento da questão tratada no texto.

A estrutura hierárquica, ao descrever todo esse processo, constitui um instrumento de análise importante para o estudo da imprecisão da ancoragem dos atos em uma informação da memória discursiva. Como vimos no estudo do fragmento 1, nesse caso, ocorre uma multiplicidade não intencional de pontos de ancoragem para um mesmo ato, não sendo possível decidir com segurança qual desses pontos constitui o tópico. Uma análise linear como a possibilitada pela estrutura informacional não permite explicar por que um determinado ato se ancora em mais de um ponto de ancoragem e não permite verificar qual desses pontos constitui o tópico. Mas a combinação da estrutura informacional com a hierárquica permite verificar a hierarquia dos tópicos e, consequentemente, fornece indicações sobre o grau de saliência das informações na memória discursiva (GROBET, 2000; CUNHA, 2009). Assim, as informações ativadas em constituintes principais são as que possuem nível de importância mais elevado, na medida em que são as essenciais para a manutenção do sentido do texto.

Para estudar a ancoragem do ato (19) do fragmento 1 (atos 14-22) em informações da memória discursiva, será preciso levar em conta também a porção textual imediatamente anterior a esse fragmento, pois é nessa porção, formada pelos atos (09-13), que a informação "o aluno" é ativada. A estrutura a seguir combina as estruturas informacional e hierárquica do segmento formado pelos atos $(09-22){ }^{6}$

6 Intervenção = I; ato = A; $\mathrm{p}=$ principal; $\mathrm{s}=$ subordinado. 
Figura 3 - Estrutura hierárquica do fragmento 1

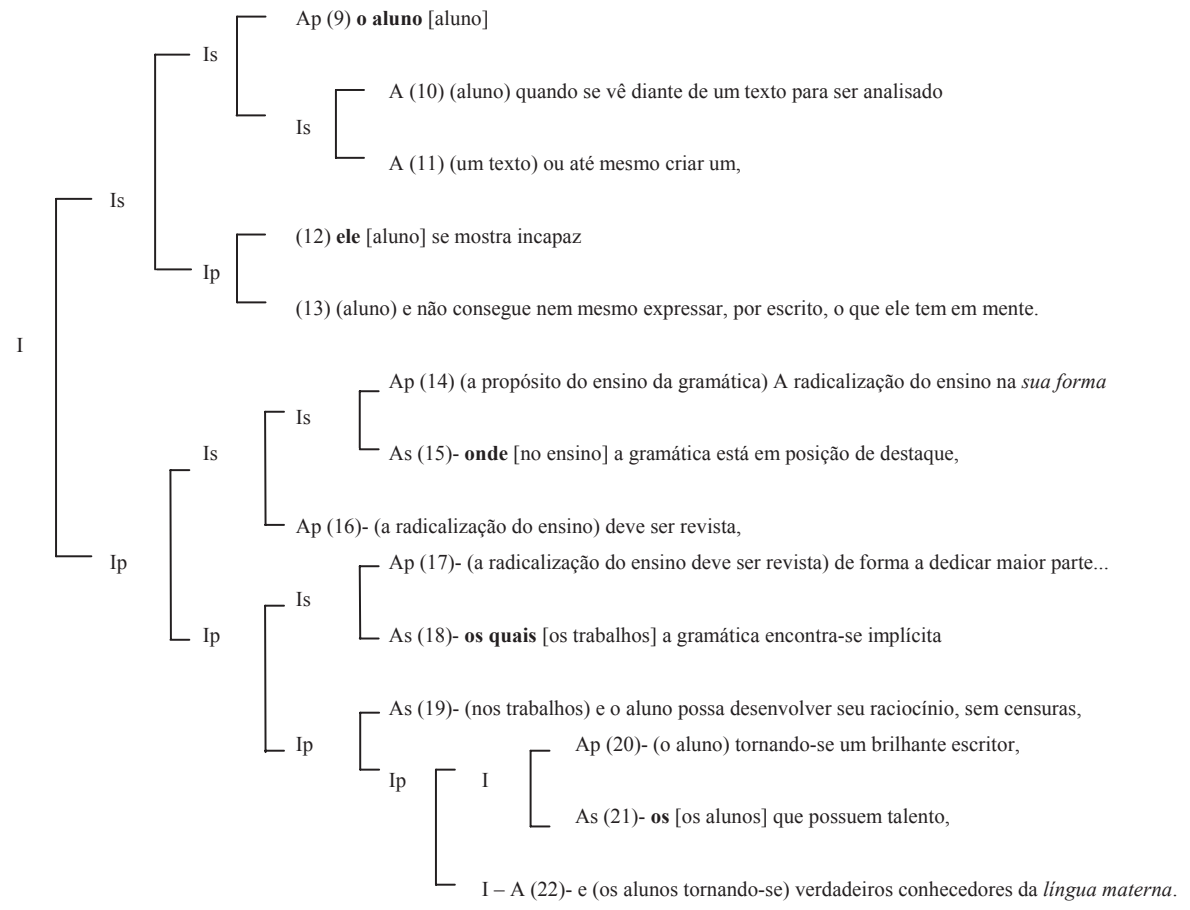

Fonte: Elaboração própria.

Como foi dito na análise da estrutura informacional do fragmento 1, o tópico do ato (19) pode ser "nos trabalhos" ou "o aluno". A informação "os trabalhos" é o tópico de (18), o que revela ser essa informação bastante acessível e, portanto, um tópico possível para (19). Mas a expressão "o aluno" se refere a uma informação já estocada na memória discursiva, que também pode constituir o tópico de (19).

Na Figura 3, verifica-se que a informação "o aluno" foi ativada na intervenção subordinada (Is 09-13) que antecede imediatamente a intervenção formada pelo fragmento 1. Nessa intervenção subordinada, a informação "o aluno" constitui o tópico de quase todos os atos, tanto dos principais quanto dos subordinados. A ancoragem dos atos dessa intervenção no tópico "o aluno" revela que, no momento da produção do fragmento 1 (atos 14-22), essa informação era bastante acessível, podendo constituir o tópico de qualquer ato desse fragmento. Isso pode explicar a opção do autor por colocar a expressão nominal definida "o aluno" como sujeito do ato (19) e, em consequência, a possibilidade de o leitor ancorar esse ato na informação "o aluno". 
Mas a estrutura também revela que a informação "nos trabalhos" foi ativada em um ato principal, o (17). Dessa forma, a possibilidade de "nos trabalhos" ser o tópico de (19) não se deve apenas à proximidade entre a origem da informação e o ato (19), mas também ao estatuto hierárquico principal do ato que ativa "nos trabalhos". Sendo assim, a combinação das estruturas informacional e hierárquica fornece indícios suplementares a favor da hipótese de que o tópico de (19) é "nos trabalhos" e não "o aluno". Embora "o aluno" seja uma informação acessível, "nos trabalhos" é uma informação que, além de estar mais próxima de (19) e de ser o tópico de (18), foi ativada em um constituinte principal da estrutura hierárquica. Nesse caso, a ambiguidade se deve ao fato de que o autor colocou em posição de sujeito um traço de segundo plano, que é a expressão definida "o aluno".

Com essa análise, verifica-se que a determinação do tópico de um ato requer muitas vezes ultrapassar um estudo linear, que se vale apenas da estrutura informacional, avançando para um estudo mais complexo, que leva em conta a hierarquia das informações ativadas. Uma análise desse tipo permite ao estudioso entender por que um determinado ato pode se encadear em mais de uma informação da memória discursiva e perceber qual dessas informações é o tópico. Em se tratando de textos de estudantes, essa análise permite ao professor entender por que, em determinadas passagens, um texto parece pontualmente desconexo ou parece fugir do tópico que vinha sendo abordado.

No item a seguir, vamos combinar a estrutura informacional com a estrutura conceitual, para compreendermos os fenômenos de construção textual ilustrados pelos fragmentos 2 e 3 .

\section{Módulo referencial}

Antes de combinarmos as estruturas informacional e conceitual, vamos apresentar de modo sucinto o módulo referencial. No estudo desse módulo, considera-se que as ações discursivas e os conceitos ativados no texto são parcialmente regulados por expectativas tipificantes. Nas interações efetivamente realizadas, essas expectativas atualizam-se em configurações particulares, que constituem o produto emergente da negociação instaurada entre os interlocutores ao longo de um dado discurso. Dessa maneira, o módulo referencial se ocupa tanto da descrição de representações esquemáticas (praxeológicas e conceituais), referentes às expectativas tipificantes subjacentes ao discurso, quanto da descrição de estruturas emergentes (praxeológicas e 
conceituais), referentes às configurações particulares e resultantes de realidades discursivas específicas (FILLIETTAZ, 1996; ROULET; FILLIETTAZ; GROBET, 2001).

Em função das representações esquemáticas, as informações ativadas no discurso se organizam em estruturas conceituais emergentes, que desempenham, segundo Roulet (1999a, p. 156), "um papel determinante na organização tópica." Essas estruturas visam a explicitar os conceitos efetivamente negociados em uma interação particular, descrevendo quais deles são primitivos e quais são derivados, assim como os mecanismos de derivação ou as relações observáveis entre esses conceitos. Descrevendo os mecanismos de derivação por meio da relação entre conceitos primitivos e derivados, " [...] a análise da estrutura conceitual permite dar conta dos elos conceituais entre as representações mentais, bem como do papel central de alguns referentes no discurso." (GROBET, 2000, p.342). Grobet aproxima a noção de conceito primitivo da noção de entidade tópica, tal como proposta por Brown e Yule (1983): "Na estrutura conceitual, a entidade tópica pode ser definida como a representação mental de um referente ativado pelo discurso (ou pela situação), a partir da qual outras informações são derivadas." (GROBET, 2000, p. 343).

Com o auxílio da estrutura conceitual, é possível verificar que, nos casos em que o autor apresenta dificuldades em estabelecer a progressão textual, há um conceito primitivo bastante relevante para o contexto de produção do texto, conceito do qual o autor não quer (ou não consegue) abrir mão, impedindo que o discurso avance.

Na análise do fragmento 2, vimos que esse conceito primitivo relevante é "o aluno" e que a esse conceito são encadeadas várias informações pouco significativas. Esse procedimento de construção textual teve como resultado um texto pouco consistente, já que se baseia na listagem de informações do senso comum a respeito de um determinado tópico. Ao proceder dessa forma, o texto revela um autor pouco hábil em transformar um conceito derivado em um novo conceito primitivo, recurso por meio do qual o texto, sem perder a continuidade, poderia progredir do ponto de vista informacional. Com a acoplagem das estruturas informacional e conceitual do fragmento 2, é possível verificar esse processo: 
Figura 4 - Estrutura conceitual do fragmento 2

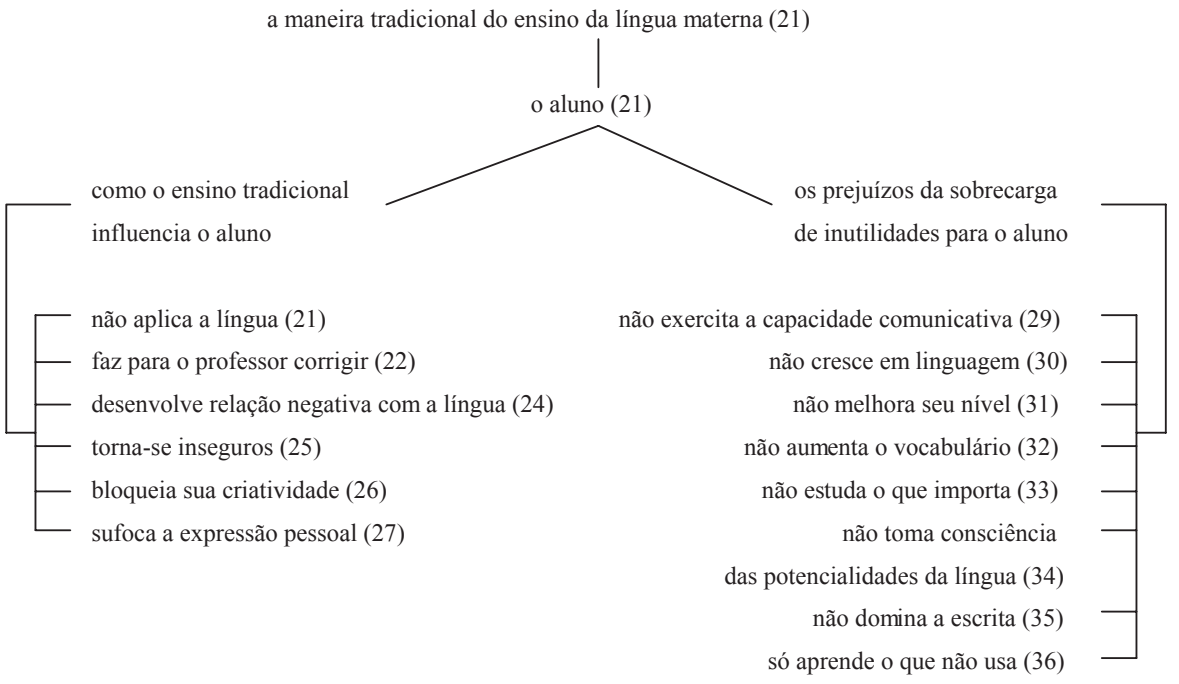

Fonte: Elaboração própria.

Essa estrutura explicita bem o papel de entidade tópica que o conceito "o aluno" exerce. Desse conceito derivam dois outros. De um lado, o autor trata de "como o ensino tradicional influencia o aluno", derivando desse conceito as atitudes do aluno em função desse ensino. De outro lado, o autor aborda "os prejuízos da sobrecarga de inutilidades para o aluno", derivando desse conceito os diferentes prejuízos decorrentes do ensino tradicional. A pouca articulação das ideias derivadas de "o aluno" se manifesta no efeito de lista que a Figura 4 evoca. De fato, as ideias são simplesmente justapostas no texto. Se há alguma articulação dessas ideias, permitindo ao leitor atribuir coerência ao texto, essa articulação se deve à ancoragem de todas elas a uma mesma entidade tópica, "o aluno".

A estrutura da Figura 4 permite explicar ainda a impressão de que muitas das informações ativadas nos atos são pouco relevantes do ponto de vista semântico ou informativo. Essa impressão ou efeito parece se dever ao fato de que cada conceito é ativado em um único ato e não é articulado a outros conceitos em atos subsequentes. Ou seja, o autor não relaciona o conceito ativado em um ato a outros conceitos, estabelecendo relações de semelhança, equivalência, oposição entre ideias distintas.

Vejamos como exemplo o ato (31). Nele, o autor informa que a sobrecarga de inutilidades não permite ao aluno melhorar seu nível. Mas em que essa sobrecarga não permite a melhora de nível do aluno? Além disso, o que seria o nível do aluno? O autor refere-se ao ano letivo em que o aluno se encontra ou ao nível de 
linguagem com que o aluno entra na escola? Essa série de questões poderia ser elucidada se o autor derivasse outros conceitos do conceito "não melhora seu nível", trazendo esclarecimentos, justificativas, explicações, comentários que dessem sustentação ao que considera um prejuízo para o aluno.

A estrutura conceitual também constitui uma ferramenta importante de análise de textos que se caracterizam pela dificuldade no estabelecimento da continuidade informacional. Nesse caso, ilustrado pelo fragmento 3, os atos sempre se encadeiam nas informações ativadas nos atos imediatamente precedentes, criando o efeito de que o autor não se fixa em um tópico determinado, dificultando a percepção do tópico discursivo e, em consequência, a construção de um universo textual coerente.

No fragmento 3, por exemplo, o autor parece não conseguir estabelecer com precisão qual o "fio condutor" do texto, já que uma informação recentemente ativada passa a constituir de imediato o tópico do ato subsequente, o que faz com que o texto se assemelhe a um conjunto desconexo de informações novas. Com a acoplagem das estruturas informacional e conceitual, é possível ultrapassar a interpretação linear obtida apenas com a estrutura informacional e proceder a uma análise mais rigorosa. A Figura 5, que trata do fragmento 3, exemplifica essa acoplagem:

Figura 5 - Estrutura conceitual do fragmento 3

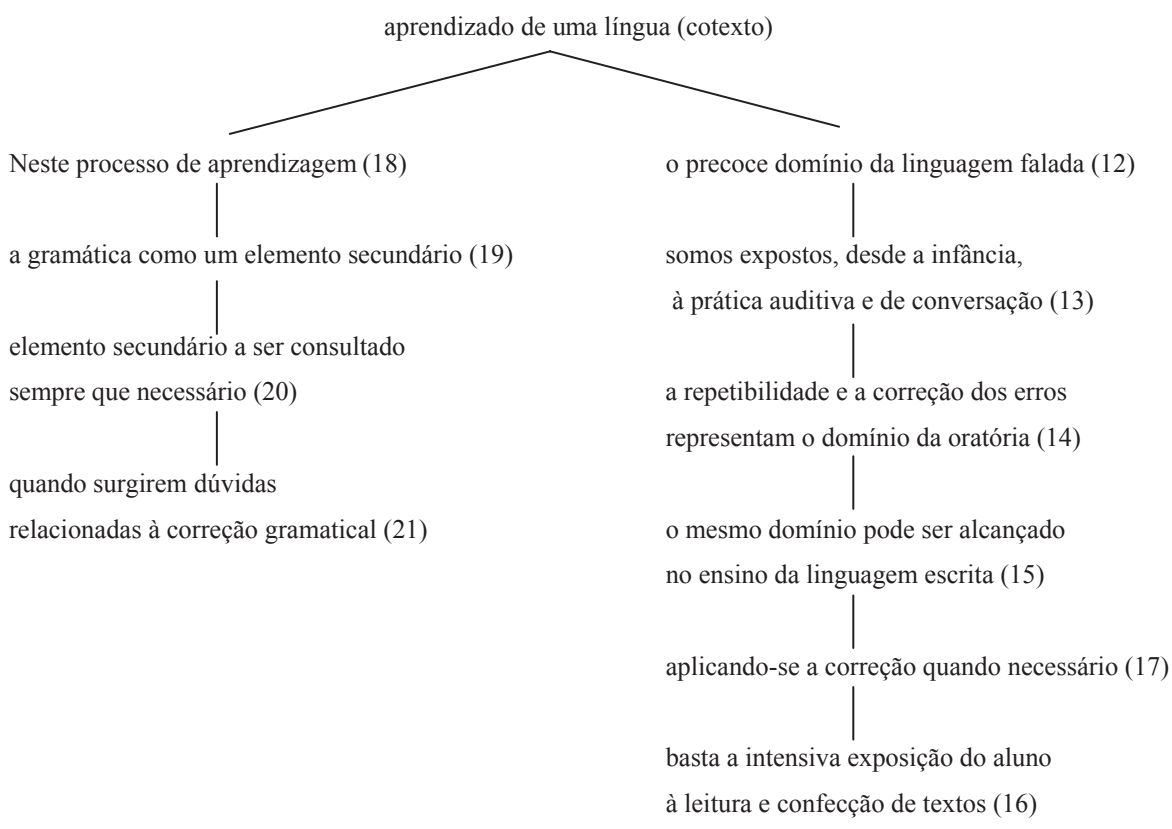

Fonte: Elaboração própria. 
Como bem mostra essa estrutura, no recurso de construção textual que privilegia a progressão linear como modo de encadeamento, o autor não deriva vários conceitos de um único conceito primitivo. Nessa estratégia de construção textual, o autor ativa um conceito. Após essa ativação, o conceito passa a constituir informação semiativa na memória discursiva. Essa informação semiativa, por sua vez, passa a constituir o tópico do ato seguinte.

Vejamos como esse processo ocorre por meio da análise dos atos (14) e (15). Com o ato (14), ocorreu a ativação do conceito "a repetibilidade e a correção dos erros representam o domínio da oratória". Uma vez ativado, esse conceito constitui uma informação que pode funcionar como o tópico de atos seguintes. Em (15), o autor informa que "o mesmo domínio pode ser alcançado no ensino da linguagem escrita". Essa informação indica que o autor encadeou o ato (15) na informação ativada em (14), já que continua tratando do domínio da oratória, o que é indicado, em (15), pelo traço tópico "o mesmo sucesso".

Ao ser usada como recurso sistemático de construção textual, a progressão linear pode fazer com que o autor passe sucessivamente pelos tópicos, sem se fixar em nenhum deles. Em muitos casos, quando o autor procede dessa forma, torna-se problemática a percepção da entidade tópica ou do conceito primitivo do texto, percepção que é decisiva para a construção da coerência por parte do leitor. Os textos em que essa percepção não é possível são aqueles classificados muitas vezes como "sem pé nem cabeça".

Mas, no fragmento em análise, se o autor exige do leitor um maior esforço na construção da coerência do texto, ao encadear as informações de maneira sucessiva em vários tópicos, é preciso levar em conta o papel da entidade tópica "aprendizado de uma língua". É ela que garante ao texto uma continuidade informacional mínima, já que permite ao leitor compreender que todos os conceitos ativados (o precoce domínio da linguagem falada, a prática auditiva e de conversação, o ensino, a gramática como elemento secundário, etc.) derivam desse conceito primitivo. Em função dessa entidade tópica, o fragmento 3, ainda que não se fixe em um tópico, não pode ser visto como "sem pé nem cabeça".

\section{Considerações finais}

Neste artigo, buscamos mostrar que o Modelo de Análise Modular do Discurso constitui uma abordagem teórico-metodológica bastante relevante para o estudo das produções discursivas de modo geral e, mais especificamente, daquelas realizadas por estudantes. Focalizando o estudo da construção da cadeia referencial em fragmentos de textos produzidos por estudantes universitários, mostramos que o estudo da forma de organização tópica pode ser de grande 
valia na percepção de dificuldades que estudantes muitas vezes manifestam no estabelecimento dessa cadeia referencial.

Nosso estudo partiu da hipótese de que esses textos constituem índices essenciais para a avaliação das capacidades de uso da linguagem dos estudantes que os produziram. Por isso mesmo, uma análise como a desenvolvida aqui pode funcionar como um ponto de partida precioso para o planejamento de atividades que auxiliem o estudante no desenvolvimento das habilidades necessárias para a construção da cadeia referencial de novos textos. Porém, é preciso ressaltar que, para que os textos de estudantes constituam índices para a avaliação de suas capacidades de uso da linguagem, o professor deverá estar munido de ferramentas de análise que, tais como as que são propostas pelo modelo modular, lhe permitam ultrapassar uma abordagem meramente intuitiva do discurso.

MARINHO, J. H. C. ; CUNHA, G. X. The reference chain construction in texts produced by university students. Alfa, São Paulo, v.58, n.1, p.11-33, 2014.

- ABSTRACT: Focusing on reference chain construction in academic texts fragments, the main purpose of this paper is, to show that the analysis of the topic organization of these texts enables the perception of difficulties that students demonstrate in establishing reference chain. Through these analyses, we identify and explain weaknesses on building this chain, such as ambiguities in recognition of topics as well as difficulties in introducing new pieces of information and in maintaining a discourse topic. Moreover, with these investigations, we verified that academic texts constitute essential indexes for evaluation the language use skills of their producers. Therefore, these studies may serve as a valuable starting point for planning activities that might assist students in developing necessary skills to reference chain construction of new texts. Therefore, we consider that the Modular Approach to Discourse Analysis constitutes a relevant approach to the study of texts produced by university students.

- KEYWORDS: Academic Texts. Reference Chain. Modular Approach.

\section{REFERÊNCIAS}

BERRENDONNER, A. Connecteurs pragmatiques et anaphore. Cahiers de Linguistique Française, Genève, n.5, p.215-246, 1983.

BROWN, G.; YULE, G. Discourse Analysis. Cambridge: Cambridge University Press, 1983.

CUNHA, G. X. O tratamento do tópico em uma perspectiva modular da organização do discurso. Estudos Linguísticos, Campinas, v.38, p.125-135, 2009.

O sequenciamento de textos como estratégia discursiva: uma abordagem modular. 2008. 250 f. Dissertação (Mestrado em Linguística) - Faculdade de Letras, Universidade Federal de Minas Gerais, Belo Horizonte, 2008. 
FILLIETTAZ, L. Vers une approche interactionniste de la dimension référentielle du discours. Cahiers de Linguistique Française, Genève, n.18, p.33-64, 1996.

GROBET, A. L'organisation informationnelle: aspects linguistiques et discursifs. Journal of French Language Studies, Cambridge, v.11, p.71-87, 2001.

L'identification des topiques dans les dialogues. 2000. 513f. Tese (Doutorado em Linguística) - Faculdade de Letras, Universidade de Genebra, Genebra, 2000.

L'organisation informationnelle du discours dialogique: la thématisation comme phénomène d'ancrage. In: GUIMIE, C. (Éd.). La thématisation dans les langues. Berne: Lang, 1999. p.405-420.

KOCH, I. G. V. Desvendando os segredos do texto. São Paulo: Cortez, 2006.

MACHADO, A. R. Os textos de alunos como índices para avaliação das capacidades de linguagem. In: MARI, H. et al. Análise do discurso em perspectivas. Belo Horizonte: FALE/UFMG, 2003. p.215-230.

MARINHO, J. H. C. A organização informacional em Uma História Distraída, de Cida Chaves. In: MELLO, R. (Org.). Análise do Discurso \& Literatura. Belo Horizonte: NAD/FALE/UFMG, 2005. p.295-308.

. O funcionamento discursivo do item "onde": uma abordagem modular. 2002. 305f. Tese (Doutorado em Linguística) - Faculdade de Letras, Universidade Federal de Minas Gerais, Belo Horizonte, 2002.

MARINHO, J. H. C.; PIRES, M. S. O.; VILLELA, A. M. N. (Org.). Análise do discurso: ensaios sobre a complexidade discursiva. Belo Horizonte: CEFET-MG, 2007.

MOTTA-ROTH, D.; HENDGES, G. R. Produção textual na universidade. São Paulo: Parábola, 2010.

NEVES, M. H. M. Gramática e texto. São Paulo: Contexto, 2006.

PERINI, M. A. Estudos de gramática descritiva. São Paulo: Parábola, 2008.

PIRES, M. S. Estratégias discursivas na adolescência. São Paulo: Arte e Ciência/ UNIP, 1997.

RONCARATI, C. As cadeias do texto: construindo sentidos. São Paulo: Parábola, 2010.

ROULET, E. Une approche modulaire de la problematique des relations de discours. In: MARI, H. et al. Análise do discurso em perspectivas. Belo Horizonte: FALE/ UFMG, 2003. p.149-178.

La description de l'organisation du discours: du dialogue au texte. Paris: Didier, 1999a. 
. Um modelo e um instrumento de análise sobre a organização do discurso. In: MARI, H. et al. (Org.). Fundamentos e dimensões da Análise do Discurso. Belo Horizonte: Carol Borges Ed., 1999b. p.139-166.

Une description modulaire de l'organisation topicale d'un fragment d'entretien. Cahiers de Linguistique Française, Genève, n.18, p.11-32, 1996.

ROULET, E.; FILLIETTAZ, L.; GROBET, A. Un modèle et un instrument d'analyse de l'organisation du discours. Berne: Lang, 2001.

Recebido em agosto de 2012.

Aprovado em janeiro de 2013. 
